\title{
Treatment With Bovine Gallstones Exacerbates Liver Damage, but Enhances Hepatoprotection by Bear Gall Powder in Carbon Tetrachloride-Intoxicated Rats
}

\author{
Toshiaki Nakashima, Ninko Matsumoto and Kei Kashima \\ Third Department of Internal Medicine, Kyoto Prefectural University of Medicine, Kawaramachi-Hirokoji, Kamigyo-ku, Kyoto 602, Japan
}

Received September 3, 1997 Accepted December 17, 1997

\begin{abstract}
The interactions between bovine gallstones (Goou) and bear gall powder (Yutan) in decreases in serum transaminase levels were investigated in rats intoxicated with carbon tetrachloride $\left(\mathrm{CCl}_{4}\right)$. The p.o. administration of Goou significantly increased both serum transaminase levels and hepatic lipid peroxidation following i.p. administration of $\mathrm{CCl}_{4}$. Concomitant administration of both Goou and Yutan resulted in decreases of serum transaminase levels and hepatic lipid peroxidation, which were more remarkable than with administration of Yutan alone. Goou significantly increased the estimated hepatic blood flow in the indocyanine green clearance test and enhanced the delivery of $\mathrm{CCl}_{4}$ to the liver from the peritoneal cavity. These findings suggest that Goou exacerbates $\mathrm{CCl}_{4}$-induced hepatic damage because of the accelerated delivery of $\mathrm{CCl}_{4}$ to the liver and that Goou might have a hemodynamic drug interaction with Yutan in the liver, possibly enhancing the hepatoprotective effect of Yutan.
\end{abstract}

Keywords: Animal crude drug, Bovine gallstone, Bear gall powder, Carbon tetrachloride, Liver

Chinese animal crude drugs such as bovine gallstones (BEZOAR BOVIS, "Goou" in Japanese) and bear gall powder (FEL URSI, "Yutan" in Japanese) have long been said to be effective for liver diseases in the Orient $(1,2)$. Goou consists mainly of bilirubin, cholesterol and cholic acid as a bile acid (3). Yutan consists mainly of ursodeoxycholic acid (UDCA) as a bile acid and taurine as an amino acid (4). We published a preliminary clinical report on the effectiveness of Goou and Yutan for the treatment of chronic liver diseases (5). This report revealed for the first time that the concomitant administration of both Goou and Yutan remarkably decreased the transaminase levels of hepatitis patients, but the actual mechanisms of the pharmacological effects of Goou and Yutan have not been clarified.

In this study, we tried to determine the effects of Goou and Yutan on carbon tetrachloride $\left(\mathrm{CCl}_{4}\right)$-intoxicated rats livers and to discuss Goou's hemodynamic interaction with $\mathrm{CCl}_{4}$ or Yutan.

\section{MATERIALS AND METHODS}

\section{Chemicals}

Goou and Yutan were obtained from Itoh Kampo Co.
(Osaka). They had been importing them from a Hong Kong trader, who obtained Goou from Australian and North American cows and Yutan from Southeast Asian and Himalayan bears, long before the so-called Washington convention (Convention on International Trade in Endangerous Species of Wild Fauna and Flora) to protect wild animals came into effect in January 1988.

Reagents used were obtained from the following commercial sources: $\mathrm{CCl}_{4}, 2$-thiobarbituric acid (TBA), tetraethoxypropane and $\alpha$, $\alpha$-diphenyl- $\beta$-picrylhydrazyl (DPPH) (Tokyo Kasei Co., Tokyo); NADPH (Sigma Chemical Co., St. Louis, MO, USA); ${ }^{14} \mathrm{CCl}_{4}$ (New England Nuclear Co., Boston, MA, USA); and indocyanine green (ICG) (Daiichi Pure Chemicals Co., Ltd., Tokyo). Other chemicals used were guaranteed grade and were obtained locally.

\section{Animals}

Male Wistar rats weighing $200 \mathrm{~g}$ were used in all experiments. Animals received a single dose of $\mathrm{CCl}_{4}(2 \mathrm{ml} / \mathrm{kg}$, b.w., i.p.) in olive oil and simultaneously given once an aqueous solution of Goou $(10,50 \mathrm{or} 100 \mathrm{mg} / \mathrm{kg}$, b.w.) and /or Yutan $(10,50$ or $100 \mathrm{mg} / \mathrm{kg}$, b.w.) through a gastric tube. Control animals were received olive oil instead of 
$\mathrm{CCl}_{4}$, and $0.9 \%$ sodium chloride instead of Goou or Yutan solution. Maintenance of animals and experimental procedures were carried out in accordance with the guidelines of The Japanese Pharmacological Society.

\section{Serum transaminase levels and ICG clearance}

The blood was collected from the portal vein of the rats anesthetized by pentobarbital $(50 \mathrm{mg} / \mathrm{kg}$, i.p.), and serum transaminase levels were measured using a GOT-UV Test kit and a GPT-UV Test kit (Wako Pure Chemicals Industries, Ltd., Osaka).

The ICG concentration in serum was measured spectrophotometrically (UV-2100S spectrophotometer; Shimadzu, Kyoto) from the absorbance at $805 \mathrm{~nm}$ in the anesthetized rats $15 \mathrm{~min}$ after administration of 0.5 $\mathrm{mg} / \mathrm{kg}$ of ICG through the teil vein (6).

\section{Lipid peroxidation and antioxidants}

The lipid peroxides formed in the liver were quantitated according to the method of Ohkawa et al. (7). Briefly, tissue homogenate was mixed with sodium dodecyl sulfate, acetate buffer (adjusted to $\mathrm{pH} 3.5$ with $\mathrm{NaOH}$ ) and an aqueous solution of TBA. After heating at $95^{\circ} \mathrm{C}$ for 60 min in a water-bath, the red color formed was extracted with a $n$-butanol-pyridine $(15: 1)$ mixture, and the intensity of the color was estimated spectrophotometrically from the absorbance at $532 \mathrm{~nm}$. Tetraethoxypropane was used as a standard for the assay, and lipid peroxide contents was expressed as nmoles of malonic dialdehyde (MDA), namely, TBA-reactive substance (TBA-RS), formed per mg protein. Protein was determined by the method of Lowry et al. (8) with bovine serum albumin as the standard.

The levels of water-soluble and fat-soluble antioxidants in the liver were determined by using a stable free radical, $\mathrm{DPPH}$, according to the procedure of Glavind (9).

\section{Cytochrome $P_{450}$ and drug metablism}

Microsomes were prepared from $0.25 \mathrm{M}$ sucrose homogenates of the liver from rats according to the procedure of Hogeboom (10) as follows: The homogenate was centrifuged at $24,000 \times g$ for $10 \mathrm{~min}$, and the supernatant thus obtained was further centrifuged at $105,000 \times g$ for $60 \mathrm{~min}$ to obtain the microsomal fraction. The microsomal pellets were suspended in $0.15 \mathrm{M} \mathrm{KCl}$, kept in an ice-cold tube and used within $8 \mathrm{hr}$ for each determination.

Hepatic microsomes, which were prepared from rats $24 \mathrm{hr}$ after dosing with Goou and/or Yutan $(50 \mathrm{mg} / \mathrm{kg}$, b.w., p.o.), were used to study drug metablism. The content of cytochrome $\mathrm{P}_{450}$ was determined by the method of Omura and Sato (11). The hexobarbital oxidation and aniline hydroxylation were assayed spectrophotometrical- ly by the methods of Cooper and Brodie (12) and Kato and Gillette (13), respectively.

\section{Lipid peroxidation in microsomes}

The extent of $\mathrm{CCl}_{4}$-induced lipid peroxidation in microsomes in vitro was estimated by measuring TBA-RS formed in the incubation media $(14,15)$. Briefly, liver microsomes ( $2 \mathrm{mg}$ protein) were preincubated with Goou and/or Yutan $(0.1 \mathrm{mg})$ at $37^{\circ} \mathrm{C}$ for $2 \mathrm{~min}$ with $0.2 \mathrm{M}$ potassium phosphate buffer ( $\mathrm{pH} 7.5$ ) containing $400 \mu \mathrm{M}$ NADPH in a final volume of $2 \mathrm{ml}$. After the addition of 2 $\mu \mathrm{mol}$ of $\mathrm{CCl}_{4}$, they were incubated for $30 \mathrm{~min}$ in tightly capped test tubes. The reaction was stopped by adding 0.2 $\mathrm{ml}$ of $8.1 \%$ sodium dodecyl sulfate and $1.5 \mathrm{ml}$ of $20 \%$ acetic acid (pH 3.5) in an ice cold water bath. Under the same experimental conditions, the blank level of TBA-RS formation was measured in the absence of NADPH and was subtracted from each experimental value.

\section{${ }^{14} \mathrm{CCl}_{4}$ metabolism in microsomes}

Liver microsomes ( $2 \mathrm{mg}$ protein) were preincubated with Goou and/or Yutan $(0.1 \mathrm{mg})$ and then further incubated at $37^{\circ} \mathrm{C}$ for $2.5,5,15$ and $30 \mathrm{~min}$ with $0.2 \mathrm{M}$ potassium phosphate buffer (pH 7.5) containing $0.8 \mu \mathrm{mol}$ of $\mathrm{CCl}_{4}$ with ${ }^{14} \mathrm{CCl}_{4}, 200 \mu \mathrm{M}$ NADPH and $3 \mathrm{mM}$ EDTA in a final volume of $2 \mathrm{ml}$. A part of the reaction mixture was placed in $10 \mathrm{ml}$ of ice cold toluene and stored at $4^{\circ} \mathrm{C}$ for 3 days with occasional shaking. An aliquot of the toluene layer was mixed with toluene scintillator containing $0.5 \%$ (W/V) PPO and $0.03 \%$ (W/V) POPOP, and then the radioactivity extracted into the toluene layer was measured by a liquid scintillation spectrometer $(16-18)$. The specific activity of the ${ }^{14} \mathrm{CCl}_{4}$ used in present experiment was $3.8 \mu \mathrm{Ci} / \mathrm{mmole}$.

\section{Distribution of ${ }^{14} \mathrm{CCl}_{4}$ in the liver}

At $0.5,1,2$ and $5 \mathrm{hr}$ after injecting $\mathrm{CCl}_{4}(2 \mathrm{ml} / \mathrm{kg}$, b.w.) containing ${ }^{14} \mathrm{CCl}_{4}$ in olive oil, intraperitoneally, the rats were sacrificed and liver specimens were taken. The liver specimens were rapidly weighed, minced and put into $10 \mathrm{ml}$ ice cold toluene and stored at $4^{\circ} \mathrm{C}$ for 3 days with occasional shaking. The radioactivity extracted into the toluene was measured as described above.

\section{Statistics}

Statistical analysis was performed by ANOVA. Differences were accepted as statistically significant at $P$ values $<0.05$.

\section{RESULTS}

Serum transaminase levels and hepatic lipid peroxidation Serum GOT and GPT significantly increased $24 \mathrm{hr}$ after 

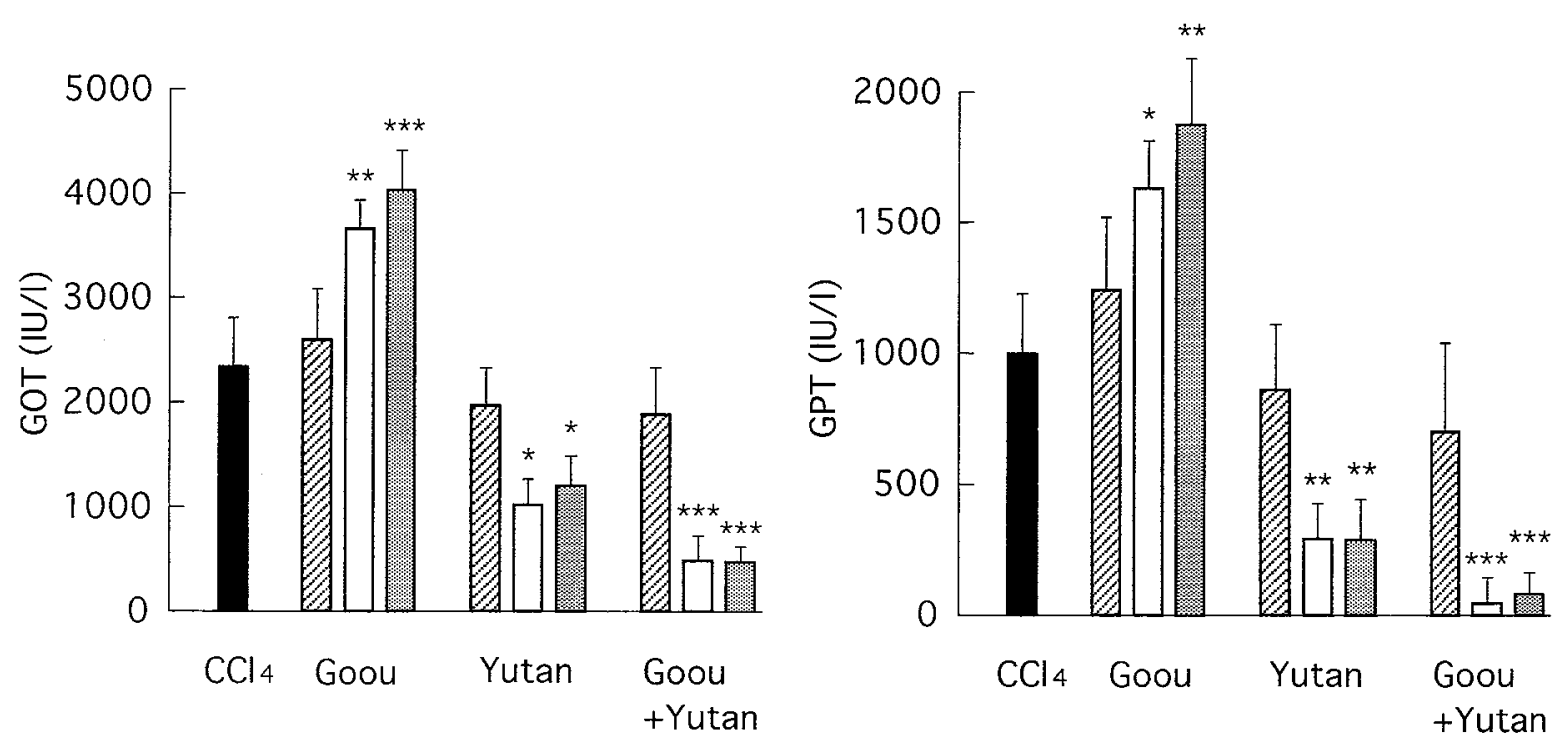

Fig. 1. Effects of Goou and Yutan on serum transaminase levels of the $\mathrm{CCl}_{4}$-treated rats. In the Goou, Yutan or Goou + Yutan group, Goou and/or Yutan $(10(\mathbb{Z}), 50(\square)$ or $100($ (娄) $\mathrm{mg} / \mathrm{kg}$ b.w., p.o.) were given simultaneously with CCl $(2 \mathrm{ml} / \mathrm{kg}$ b.w., i.p.). The rats in the $\mathrm{CCl}_{4}$ group were given saline instead of these drugs. Serum GOT and GPT were measured $24 \mathrm{hr}$ later. Each column represents the mean \pm S.E. obtained from four or five separate experiments. Control values were $45 \pm 9$ for GOT and $35 \pm 10$ for GPT $\left(n=5\right.$, mean \pm S.E.). The value obtained with $\mathrm{CCl}_{4}$ was significantly higher than the control value $(\mathrm{P}<0.001)$. ${ }^{*} \mathrm{P}<0.05,{ }^{* *} \mathrm{P}<0.01,{ }^{* * *} \mathrm{P}<0.001$, compared to the value obtained with $\mathrm{CCl}_{4}$.

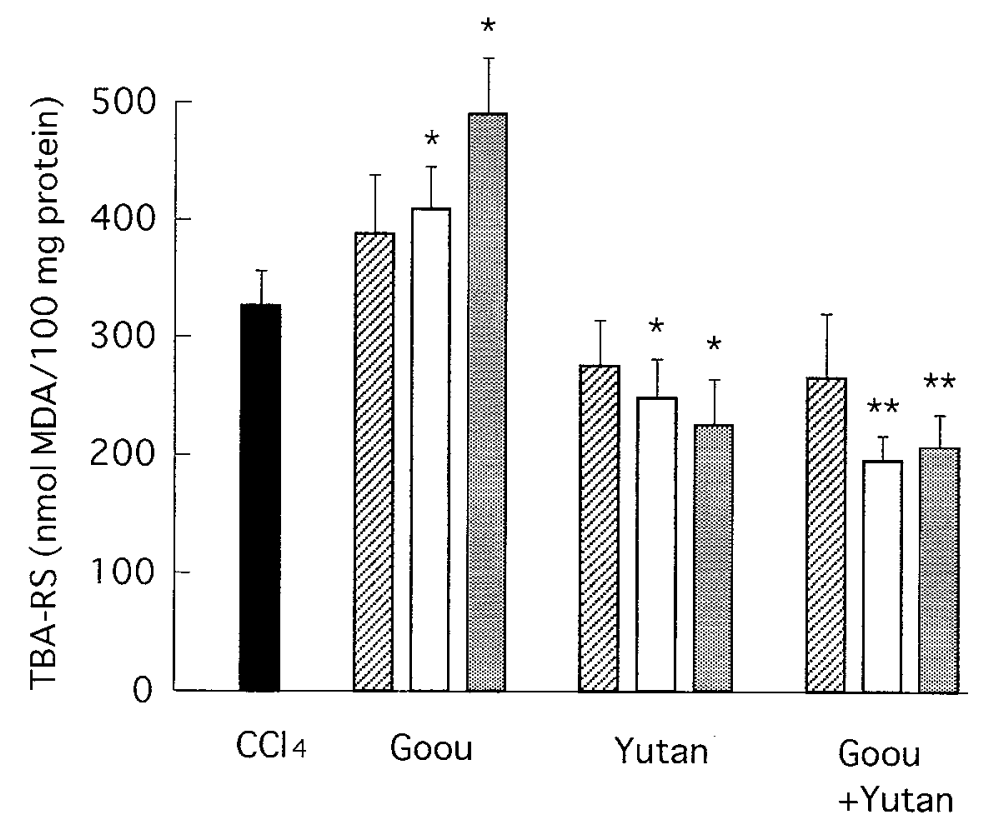

Fig. 2. Effects of Goou and Yutan on hepatic lipid peroxidation in $\mathrm{CCl}_{4}$-treated rats. The treatment with $\mathrm{CCl}_{4}$, Goou and/or Yutan was the same as described in the Fig. 1 legend. Each column represents the mean \pm S.E. obtained from four or five separate experiments. The control value was $118 \pm 20(\mathrm{n}=5$, mean \pm S.E. $)$. The value obtained with $\mathrm{CCl}_{4}$ was significantly higher than the control value $(\mathrm{P}<0.001)$. ${ }^{*} \mathrm{P}<0.05$, ${ }^{* *} \mathrm{P}<0.01$, compared to the value obtained with $\mathrm{CCl}_{4}$.

the administration of $\mathrm{CCl}_{4}$ (Fig. 1). The GOT and GPT of the $\mathrm{CCl}_{4}$-administered rats were further significantly increased by the simultaneous administration of Goou (50 or $100 \mathrm{mg} / \mathrm{kg}$ ). In contrast, GOT and GPT were found to be decreased by the administration of Yutan (50 or 100 $\mathrm{mg} / \mathrm{kg})$. The rats given both Goou and Yutan $(50$ or 100 
$\mathrm{mg} / \mathrm{kg}$ ) showed statistically significant improvements in GOT and GPT, exceeding those of rats given Yutan alone.

As shown in Fig. 2, TBA-RS in the liver increased approximately three fold at $24 \mathrm{hr}$ after the administration of $\mathrm{CCl}_{4}$. This hepatic TBA-RS was further increased by the administration of Goou ( 50 or $100 \mathrm{mg} / \mathrm{kg}$ ), but was significantly decreased by the administration of Yutan ( 50 or $100 \mathrm{mg} / \mathrm{kg}$ ). The concomitant administration of Goou and Yutan $(50$ or $100 \mathrm{mg} / \mathrm{kg}$ ) markedly decreased the hepatic TBA-RS of $\mathrm{CCl}_{4}$-administered rats.

Cytochrome $P_{450}$, hexobarbital oxidation, aniline hydroxylation and hepatic antioxidant levels

The content of cytochrome $\mathrm{P}_{450}(\mathrm{nmol} / \mathrm{mg}$ protein) was $0.34 \pm 0.02$, and oxidation of hexobarbital (nmol/30 $\mathrm{min} / \mathrm{mg}$ protein) and hydroxylation of aniline $(\mathrm{nmol} / 20$ $\mathrm{min} / \mathrm{mg}$ protein) were $5.2 \pm 0.4$ and $0.34 \pm 0.05$, respectively, in control rats $(n=5$, mean \pm S.E. $)$. Neither Goou nor Yutan affected the content of cytochrome $\mathrm{P}_{450}$, oxidation of hexobarbital or hydroxylation of aniline in hepatic microsomes (data not shown).

Hepatic antioxidants ( $\mu$ equiv/g liver) were found to be mostly of the water-soluble type $(19.8 \pm 2.5)$, and only

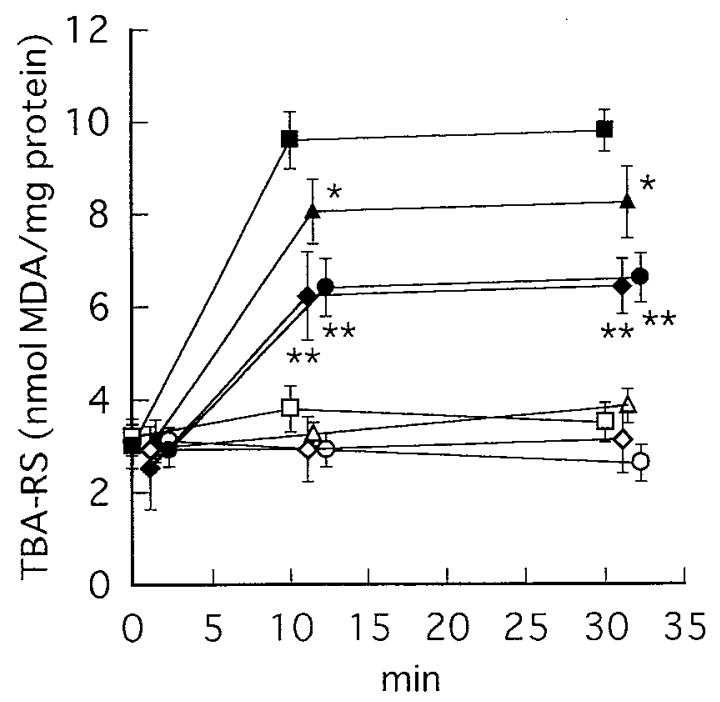

Fig. 3. Effects of Goou and Yutan on $\mathrm{CCl}_{4}$-induced lipid peroxidation in hepatic microsomes. Hepatic microsomes ( $2 \mathrm{mg}$ protein) were incubated with Goou and/or Yutan $(0.1 \mathrm{mg})$ with or without 2 $\mu \mathrm{mol}$ of $\mathrm{CCl}_{4}$. Control $(\square)$, Goou $(\bigcirc)$, Yutan $(\triangle)$, Goou + Yutan $(\diamond), \mathrm{CCl}_{4}(\square), \mathrm{CCl}_{4}+\mathrm{Goou}(\bigcirc), \mathrm{CCl}_{4}+$ Yutan $(\mathbf{A})$ and $\mathrm{CCl}_{4}+$ Goou + Yutan $(\diamond)$. Each point represents the mean \pm S.E. obtained from four separate experiments. In the $\mathrm{CCl}_{4}, \mathrm{CCl}_{4}+\mathrm{Goou}, \mathrm{CCl}_{4}+$ Yutan and $\mathrm{CCl}_{4}+\mathrm{Goou}+$ Yutan group, the values obtained at 10 and $30 \mathrm{~min}$ after the addition of $\mathrm{CCl}_{4}$ were significantly higher than each initial $(0 \mathrm{~min})$ value $(\mathrm{P}<0.001) .{ }^{*} \mathrm{P}<0.05,{ }^{* *} \mathrm{P}<0.001$, compared to the value obtained with $\mathrm{CCl}_{4}$. small amounts of fat-soluble antioxidants $(0.08 \pm 0.02)$ were detected in control rats $(n=4$, mean \pm S.E.). Goou and Yutan had no marked effect on the contents of these antioxidants (data not shown).

\section{$\mathrm{CCl}_{4}$-induced lipid peroxidation in hepatic microsomes}

As shown in Fig. 3, a marked increase in TBA-RS formation was noticed in the media containing $\mathrm{CCl}_{4}$. When the media were incubated with Goou and/or Yutan, the $\mathrm{CCl}_{4}$-induced lipid peroxidation was significantly reduced.

\section{${ }^{14} \mathrm{CCl}_{4}$ metabolism in hepatic microsomes}

The metabolic degradation of ${ }^{14} \mathrm{CCl}_{4}$ by hepatic microsomes was significantly reduced by the addition of Goou; in contrast, the addition of Yutan did not affect the metabolism of ${ }^{14} \mathrm{CCl}_{4}$ (Fig. 4).

\section{ICG clearance}

The ICG clearance test was performed in the control and the Goou and/or Yutan-treated (for 1 day) rats. As shown in Fig. 5, both drugs, especially Goou, significantly augmented ICG clearance.

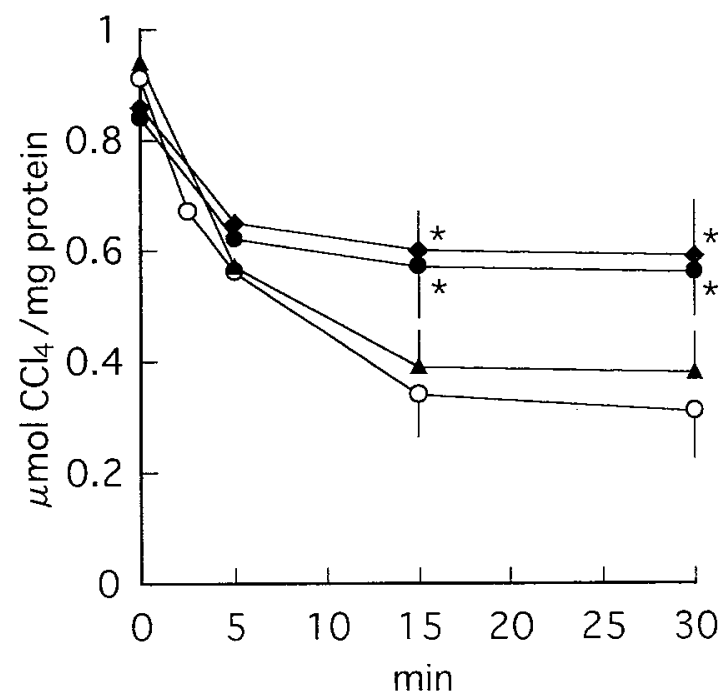

Fig. 4. Effects of Goou and Yutan on the metabolism of $\mathrm{CCl}_{4}$ in hepatic microsomes. The metabolism of $\mathrm{CCl}_{4}$ was estimated by the disappearance of radioactivity of the added ${ }^{14} \mathrm{CCl}_{4}$ in an incubation mixture containing microsomes in vitro. ${ }^{14} \mathrm{CCl}_{4}$ is converted to ${ }^{14} \mathrm{CCl}_{3}$ and the ${ }^{14} \mathrm{C}$ of $\mathrm{CCl}_{3}$ is then metabolized to ${ }^{14} \mathrm{CO}_{2}$ via the microsomal mixed function oxidase system. The ${ }^{14} \mathrm{CO}_{2}$ produced ultimately evaporates (17). Hepatic microsomes ( $2 \mathrm{mg}$ protein) were incubated with Goou and/or Yutan $(0.1 \mathrm{mg})$ with $2 \mu \mathrm{mol}$ of $\mathrm{CCl}_{4}$ containing ${ }^{14} \mathrm{CCl}_{4}$. Control (O), Goou (O), Yutan (A) and Goou + Yutan $(\diamond)$. The points represent the mean value or the mean \pm S.E. obtained from two or four separate experiments. ${ }^{*} \mathrm{P}<0.01$, compared with the Control value. 


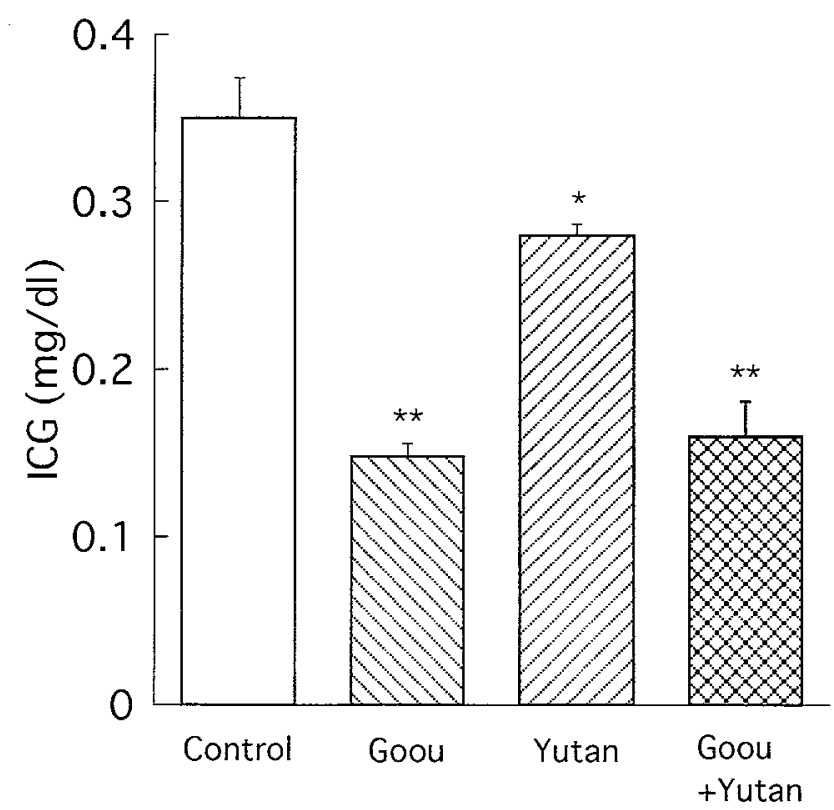

Fig. 5. Effects of Goou and Yutan on ICG clearance in rats. Rats in the test groups were given Goou and/or Yutan $(50 \mathrm{mg} / \mathrm{kg}$ b.w., p.o.), and control rats were given saline instead of these drugs. Twenty-four hours later, the concentration of ICG in serum was measured $15 \mathrm{~min}$ after the administration of ICG $(0.5 \mathrm{mg} / \mathrm{kg} \mathrm{b} . \mathrm{w}$.$) .$ Each column represents the mean \pm S.E. obtained from four separate experiments. ${ }^{*} \mathrm{P}<0.05,{ }^{*} \mathrm{P}<0.001$, compared with the Control value.

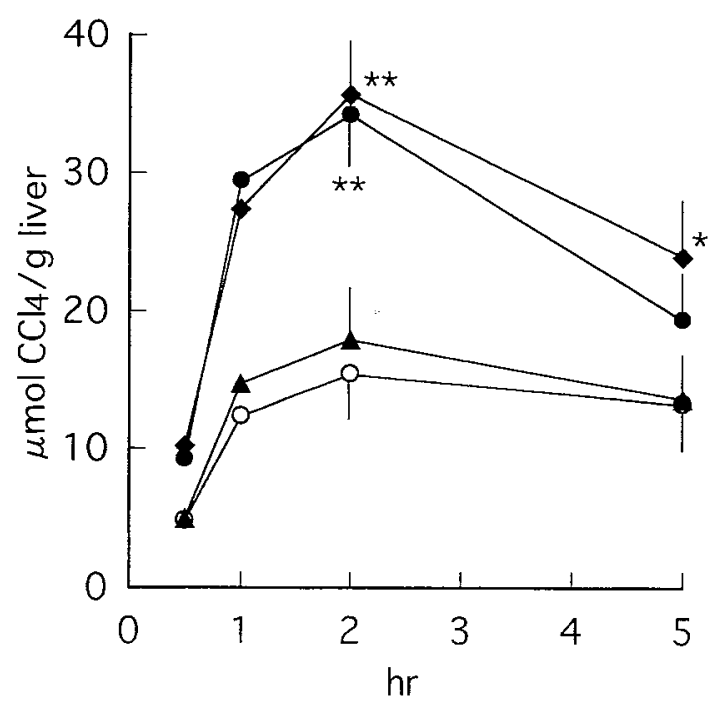

Fig. 6. Effects of Goou and Yutan on the distribution of $\mathrm{CCl}_{4}$ in the livers of rats. The amount of radioactivity in hepatic tissue was measured after the intraperitoneal administration of $\mathrm{CCl}_{4}(2 \mathrm{ml} / \mathrm{kg}$ b.w.) containing ${ }^{14} \mathrm{CCl}_{4}$. Rats were given Goou and/or Yutan (50 $\mathrm{mg} / \mathrm{kg} \mathrm{b}$.w.) or saline as a control $1 \mathrm{hr}$ before the administration of $\mathrm{CCl}_{4}$. Control $\left(\mathrm{CCl}_{4}\right.$ alone) $(\mathrm{O})$, Goou (O), Yutan $(\boldsymbol{\Lambda})$ and Goou + Yutan $(\diamond)$. The points represent the mean value or the mean \pm S.E. obtained from two or four separate experiments. ${ }^{*} \mathrm{P}<0.05$, ${ }^{* *} \mathrm{P}<0.01$, compared with the Control value.

\section{Distribution of ${ }^{14} \mathrm{CCl}_{4}$ in the liver}

After $2 \mathrm{hr}$ of dosing with $\mathrm{CCl}_{4}$ containing ${ }^{14} \mathrm{CCl}_{4}$, there was greater uptake of ${ }^{14} \mathrm{CCl}_{4}$ in the livers of rats simultaneously given Goou or Goou + Yutan as compared to animals given $\mathrm{CCl}_{4}\left({ }^{14} \mathrm{CCl}_{4}\right)$ alone (Fig. 6).

\section{DISCUSSION}

Our previous report (5) clearly demonstrated that the concomitant administration of both Goou and Yutan resulted in marked improvement of GOT and GPT in all hepatitis patients within one month. The administration of Goou alone, however, improved neither GOT nor GPT. In the present study, we have endeavored to elucidate the interaction of Goou and Yutan on the improvement of GOT and GPT using experimental injury of the rat liver.

Serum transaminase levels of $\mathrm{CCl}_{4}$-treated rats were further increased by the administration of Goou and decreased by the concomitant administration of Goou and Yutan more than the administration of Yutan alone. As hepatic lipid peroxidation is a major factor in the induction of hepatocellular necrosis following $\mathrm{CCl}_{4}$ administration (19), hepatic lipid peroxidation was then examined: the hepatic lipid peroxidation was increased by the administration of Goou and decreased by the administration of Yutan, both significantly. The concomitant administration of Goou and Yutan decreased lipid peroxidation more than the administration of Yutan alone. These findings suggest that the concomitant administration of Goou and Yutan may exert a protective action against $\mathrm{CCl}_{4}$-induced hepatocellular damage by reducing the formation of lipid peroxides in the liver, and they indicate that there may be some synergistic interaction between Goou and Yutan in decreasing hepatic lipid peroxide formation in $\mathrm{CCl}_{4}$-administered rats.

It has been well-established that $\mathrm{CCl}_{4}$ is cleaved, yielding a $\mathrm{CCl}_{3}$ radical, by the mixed function oxidase system in liver microsomes, and that the $\mathrm{CCl}_{3}$ radical reacts with unsaturated fatty acids to form lipid peroxides in the liver (19). As to these observations, the effects of Goou and Yutan administration on the activity of the microsomal mixed function oxidase system were investigated. As a result, Goou and Yutan did not influence the content of cytochrome $\mathrm{P}_{450}$ and the metabolism of drugs such as hexobarbital and aniline in hepatic microsomes. On the other hand, antioxidants can function as free radical scavengers that may decrease lipid peroxidation. Treatment with Goou and/or Yutan, however, had no effects on the antioxidant contents of the in vivo liver. These results did not explain why the administration of Goou enhanced and the concomitant administration of Goou and Yutan suppressed lipid peroxidation in the liver of 
$\mathrm{CCl}_{4}$-administered rats.

The effects of Goou and Yutan on $\mathrm{CCl}_{4}$-induced lipid peroxidation, which were demonstrated in vivo, were further investigated in vitro using hepatic microsomes. Contrary to expectation, it was found that Goou had a direct suppressive effect on $\mathrm{CCl}_{4}$-induced lipid peroxidation in hepatic microsomes. This finding suggested that Goou might prevent the metabolism of $\mathrm{CCl}_{4}$ to the $\mathrm{CCl}_{3}$ radical via the mixed function oxidase system and/or that Goou might have an antioxidative effect and thereby terminate the radical reactions. To assess these possibilities, first, the effect of Goou on the metabolic degradation of $\mathrm{CCl}_{4}$ was investigated in vitro in hepatic microsomes: the degradation of ${ }^{14} \mathrm{CCl}_{4}$ by hepatic microsomes was significantly reduced by the addition of Goou. Furthermore, Goou decolored the DPPH in the methanol solution (data not shown), indicating that Goou had antioxidant properties. The anti-oxidative effect of bilirubin, the principal ingredient of Goou, is well-known (20). The effects of Goou on $\mathrm{CCl}_{4}$-induced lipid peroxidation in vivo, therefore, cannot be explained by these effects on microsomes in vitro.

As Goou has been reported to dilate vessels and improve blood flow in organs (3), we investigated the effect of Goou on ICG clearance, which is an estimate of hepatic blood flow (21): Goou significantly accelerated hepatic blood flow. This finding suggested that Goou might enhance the transport of $\mathrm{CCl}_{4}$ from the peritoneal cavity to the liver by increasing hepatic blood flow, possibly resulting in the enhancement of $\mathrm{CCl}_{4}$-induced lipid peroxidation in the liver. In fact, it was confirmed that the hepatic distribution of ${ }^{14} \mathrm{CCl}_{4}$ following intraperitoneal injection of ${ }^{14} \mathrm{CCl}_{4}$ was enhanced by simultaneous treatment with Goou. A few previous reports have suggested the possibility that some bile acids increase blood flow in internal organs $(22,23)$, although the component of Goou contributing to the increased hepatic blood flow and the actual mechanisms remain to be elucidated.

On the other hand, the suppressive effect of Yutan on $\mathrm{CCl}_{4}$-induced lipid peroxidation was recognized not only in vivo in the liver but also in vitro in hepatic microsomes. Yutan did not suppress the metabolic degradation of $\mathrm{CCl}_{4}$ in microsomes. From these results, it can be surmised that Yutan may have a direct effect on the microsomal membrane, possibly decreasing the susceptibility of the membrane to lipid peroxide formation induced by $\mathrm{CCl}_{4}$. The main ingredient of Yutan is UDCA which has recently been used to treat chronic liver diseases such as primary biliary cirrhosis (24) and chronic hepatitis C (25). Because UDCA is a hydrophilic bile acid that is less toxic than hydrophobic bile acids such as chenodeoxycholic acid (26), it is believed that administered UDCA protects the cellular component against the toxicity of hydrophobic bile acids (27). Taurine, which is also present in Yutan, has been recognized to be a membrane stabilizer (18) and to improve GOT and GPT in liver damage (28). Our previous study (14) revealed that the suppressive effect of taurine against $\mathrm{CCl}_{4}$-induced lipid peroxidation occurs both in vivo and in vitro.

One of the interesting findings obtained in the present study is that Goou might enhance the suppressive effect of Yutan on hepatic lipid peroxidation induced by $\mathrm{CCl}_{4}$. Considering the interaction of Goou and $\mathrm{CCl}_{4}$ mentioned above, it is speculated that Goou may enhance the transport of Yutan from the intestinal cavity to the liver, resulting in the enhancement of the hepatoprotective effect of Yutan. Under these circumstances, the suppressive effect of Yutan on hepatic lipid peroxidation might be superior to the accelerating effect of Goou on hepatic lipid peroxidation. The possibility that Goou has a hemodynamic interaction with other drugs adequately explains the observation that Goou is generally used as a so-called "compound medicine" - a drug that enhances the effectiveness of other drugs - in traditional oriental medicine. For example, Rokushingan (in Japanese) contains Goou and Yutan or deer sexual glands (MOSCHUS), and Henshikou (in Japanese) contains Goou and snake bile: these drugs are also effective for liver diseases (29).

Although the present findings are based on crude extracts of heterogenous natural products, major constituents of Goou and Yutan are readily available. Therefore, it would be desirable to factor out which constituents are responsible for the intriguing effects observed. Experimental in vivo and in vitro studies based on this viewpoint are proceeding in our laboratory.

\section{REFERENCES}

1 Li S-C: Cow, gall. In Honzo Koumoku, Animal section, Vol 50-bottom, animal 1, China (1578) (in Chinese)

2 Li S-C: Bear, gall. In Honzo Koumoku, Animal section, Vol 51, animal 2, China (1578) (in Chinese)

3 Takagi K, Kimura M, Harada M and Ootsuka H: Goou. In Pharmacology of Medicinal Herbs in East Asia, p 242, Nanzando, Tokyo (1982) (in Japanese)

4 Takagi K, Kimura M, Harada M and Ootsuka H: Yutan. In Pharmacology of Medicinal Herbs in East Asia, p 135, Nanzando, Tokyo (1982) (in Japanese)

5 Matsumoto N, Nakashima T and Kashima K: Effectiveness of bovine gallstone (Goou) and bear gall powder (Yutan) on chronic liver diseases: a preliminary report. Tokai J Exp Clin Med 20, 9-16 (1995)

6 Paumgartner GP, Krains R and Leevy CM: Kinetics of indocyanine green removal from the blood. Ann NY Acad Sci 170, 134- 146 (1970)

7 Ohkawa $\mathrm{H}$, Ohishi $\mathrm{N}$ and Yagi K: Assay for lipid peroxides in animal tissues by thiobarbituric acid reaction. Anal Biochem 95, 351-358 (1979)

8 Lowry OH, Rosebrough NJ, Farr AL and Randal RJ: Protein 
measurement with the Folin phenol reagent. J Biol Chem 193, 265-275 (1951)

9 Glavind J: Antioxidants in animal tissue. Acta Chem Scand 17, $1635-1640$ (1963)

10 Hogeboom GH: Fractionation of cell components of animal tissue. Methods Enzymol 1, 16-19 (1995)

11 Omura $\mathrm{T}$ and Sato $\mathrm{R}$ : The carbon monoxide-binding pigment of liver microsomes. 1. Evidence for its hemoprotein nature. $\mathrm{J}$ Biol Chem 239, 2370-2378 (1964)

12 Cooper JR and Brodie BB: The enzymatic metabolism of hexobarbital (Evipal). J Pharmacol Exp Ther 114, 409-417 (1955)

13 Kato R and Gillette JR: Effect of starvation on NADPH-dependent enzymes in liver microsomes of male and female rats. $\mathrm{J}$ Pharmacol Exp Ther 150, 279-284 (1965)

14 Nakashima T, Takino T and Kuriyama K: Therapeutic effect of taurine administration on carbon tetrachloride-induced hepatic injury. Jpn J Pharmacol 32, 583-589 (1982)

15 Nakashima $\mathrm{T}$, Takino $\mathrm{T}$ and Kuriyama K: Pretreatment with taurine facilitates hepatic lipid peroxide formation associated with carbon tetrachloride intoxication. Jpn J Pharmacol 33, $515-523$ (1983)

16 Marchand C, McLean S and Plaa GL: The effect of SKF 525A on the distribution of carbon tetrachloride in rats. J Pharmacol Exp Ther 174, 232-238 (1970)

17 Seawright AA, Wilkie IW, Costigan P, Hrdlicka J and Steele DP: The effect of an equimolar mixture of carbon tetrachloride and carbon disulphide on the liver of the rat. Biochem Pharmacol 29, 1007-1014 (1980)

18 Nakashima T, Shima T, Sakai M, Yama H, Mitsuyoshi $\mathrm{H}$, Inaba $\mathrm{K}$, Matsumoto $\mathrm{N}$, Sakamoto $\mathrm{Y}$, Kashima $\mathrm{K}$ and Nishikawa $\mathrm{H}$ : Evidence of a direct action of taurine and calcium on biological membranes - a combined study of ${ }^{31} \mathrm{P}$-nuclear magnetic resonance and electron spin resonance. Biochem Pharmacol 52, 173-176 (1996)

19 Zimmerman HJ: Direct (toxipathic) hepatotoxin: Carbon tetrachloride. In Hepatotoxicity, Edited by Zimmerman $\mathrm{HJ}$, pp 198-210, Appleton-Century-Crofts, New York (1978)

20 Yamaguchi T, Terakado M, Horio F, Aoki K, Tanaka M and Nakajima $H$ : Role of bilirubin as an antioxidant in an ischemia-reperfusion of rat liver and induction of heme oxygenase. Biochem Biophys Res Commun 223, 129-135 (1996)

21 Caesar L, Shaldon S, Chiandussi L, Guevara L and Sherlock S: The use of indocyanine green in the measurement of hepatic blood flow and as a test of hepatic function. Clin Sci 21, 43-57 (1961)

22 Yamatake Y, Ishikawa S and Yanaura S: Effects of some bile acids on hepatic blood flow in dogs - with reference to biliary excretion. Jpn J Pharmacol 26, 273-275 (1976)

23 Finestone H, Fechner $\mathrm{C}$ and Levy M: Effects of bile and bile salt infusions on renal function in dogs. Can J Physiol Pharmacol 62, $762-768$ (1984)

24 Poupon R, Poupon RE, Calmus Y, Chretien Y, Ballet F and Darnis F: Is ursodeoxycholic acid effective treatment for primary biliary cirrhosis? Lancet I, 834-836 (1987)

25 Takano S, Ito Y, Yokosuka O, Ohto M, Uchiumi K, Hirota K and Omata M: A multicenter randomized controlled dose study of ursodeoxycholic acid for chronic hepatitis C. Hepatology 20 , 558-564 (1994)

26 Fromm H, Roat JW, Gonzalez V, Sarva RP and Farivar S: Comparative efficacy and side effects of ursodeoxycholic and chenodeoxycholic acids in dissolving gallstones: a double-blind controlled study. Gastroenterology 85, 1257-1264 (1983)

27 Guldutuna S, Zimmer G, Imhof $M$, Bhatti S, You $T$ and Leuschner U: Molecular aspects of membrane stabilization by ursodeoxycholate. Gastroenterology 104, 1736-1744 (1993)

28 Kroll $\mathrm{J}$ and Lund $\mathrm{E}$ : The effect of taurine on serum levels of aminotransferase activity in patients with cirrhosis. Danish Med Bull 13, 173-174 (1966)

29 Otsuka K, Yakazu D and Shimizu T: Rokushingan. In Standard Practice of Kampo-Medicine, p 538, Nanzando, Tokyo (1969) (in Japanese) 